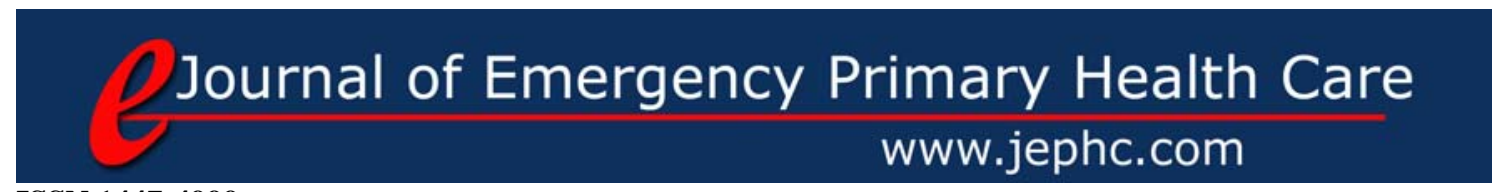

ISSN 1447-4999

\title{
EDUCATION
}

Article 990191

\section{Qualitative analysis of undergraduate paramedic students' perceptions of using case-based learning in an online learning environment}

\author{
Brett Williams \\ Lecturer, Monash University Department of Community Emergency Health and Paramedic Practice \\ Melbourne, Australia
}

\begin{abstract}
This paper presents the second paper in a series outlining the results of a recent research project that aimed to identify student paramedic perceptions of case-based learning (CBL) in the clinical curriculum of the Bachelor of Emergency Health (BEH) degree at Monash University. The integration of student-centred learning (SCL) and CBL within clinical education is an important part of undergraduate prehospital education at Monash University. This e-learning pedagogy has facilitated the creation of small online learning communities, and allowed closer scrutiny of the current technological teaching and learning environment. The study concludes that CBL is a congruent teaching methodology in clinical curricula for prehospital BEH undergraduate students.
\end{abstract}

Keywords: CBL; case based learning; online learning; paramedic studies; SCL: studentcentred learning

\section{Aims}

The goal of the study was to 'map the terrain' of students' attitudes and responses to CBL in an online teaching and learning environment whilst also investigating the pedagogical application of CBL in a blended learning environment. Educational theories from Piaget, ${ }^{1}$ Dewey $^{2}$, Bruner $^{3}$ and Vygotsky ${ }^{4}$ were used to shape and inform the data analysis of cognitivism, constructivism and social constructivism.

\section{Background}

Since first admitting students in 1961, Monash has earned its place among Australia's prestigious Group of Eight (Go8) universities with its dedication to the highest educational standards. $^{5}$ The Go8 undertakes 70 per cent of all research conducted in Australian universities and more than half of all basic research conducted throughout Australia. Monash has over 50,000 students from more than 100 countries at our ${ }^{6}$ Australian campuses and our campuses in Malaysia and South Africa. Our students also benefit from our centres in London, UK and Prato, Italy and our teaching and research partnerships around the globe. Monash offers a broad range of degrees each with a diverse range of disciplines through its 10 faculties. $^{5}$

The CBL process was used in the BEH by the author in the units of Foundations of Paramedic Clinical Practice ( $2^{\text {nd }}$ year) and Paramedic Management of Critical Care Specialty Author(s): Brett Williams 
Situations ( $3^{\text {rd }}$ year) and has been adapted and modified from the Maastricht PBL 'SevenJump’ Process ${ }^{6-8}$ and is summarised in the following terms:

1. Small tutorial groups are formed

2. The clinical case or scenario is established to develop self-discovery processes

3. The clinical case is then analysed and assimilated

4. Self-discovery of information, data, literature and clinical implications and manifestations

5. Supporting evidence, data, and patient presentation is provided as required by teachers and student tutorial members

6. Hypothesise potential answers and clinical solutions

7. Collect and disseminate new information applicable to clinical situation. ${ }^{6-8}$

Table 1. CBL process used in the BEH (adapted from the Maastricht PBL 'Seven-Jump' Process)

\section{The integration of CBL in the BEH}

Each year level of the BEH studied was divided up into three separate e-tutorial groups within WebCT TM (Vista) according to a study timetable (Table 2). The formation of tutorial groups particularly constructed in the e-learning environment is supported by Vygotsky's (1978) social learning theory, ${ }^{4}$ which claims that much of our intellectual development has direct correlation to the social interactions and group dynamics of such learning environments. This theory supports the concept that a group's perspectives and explanations to problems are reinforced through debate, disagreement, negotiation, discussion and compromise. $^{9}$

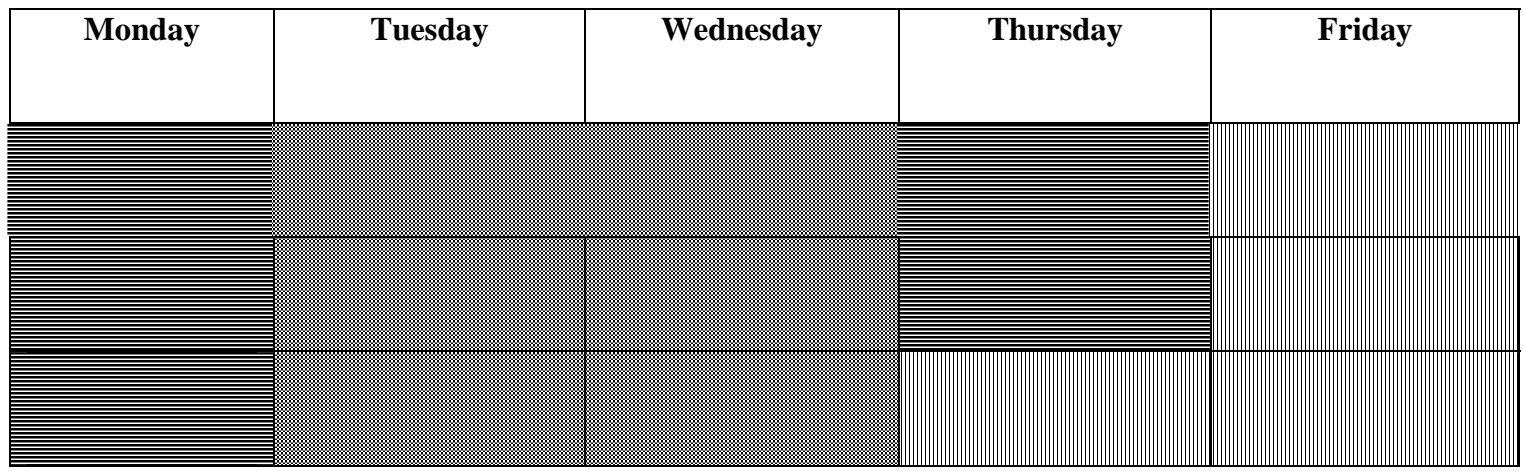

Table 2: Example of weekly structure using a blended method for second and third year students.

Legend:

\begin{tabular}{|c|c|c|}
\hline Face-to-face lectures & Brainstorming Period & Group shares answers \\
\hline
\end{tabular}

Each group is assigned a different student group leader from week-to-week whose function was not only to actively participate in the normal weekly discussion, but to write-up the groups' thoughts and questions into the 'final submissions' section. This section was separate from the tutorial 'brainstorming' area, and all three tutorial groups were allowed to view other groups' views and opinions, with the goal of stimulating further rigorous discussions and deliberations (Figure 2). For example, group A may have stated that drug ' $x$ ' should be given in certain respiratory emergencies based upon the review and analysis of the literature; however, if groups $\mathrm{B}$ and $\mathrm{C}$ disagreed with this, then further discussion and debate ensued. It was anticipated that by dividing the groups into smaller tutorial groups this would allow deliberation and dissemination of clinical practice, otherwise not necessarily achievable in a larger group. 


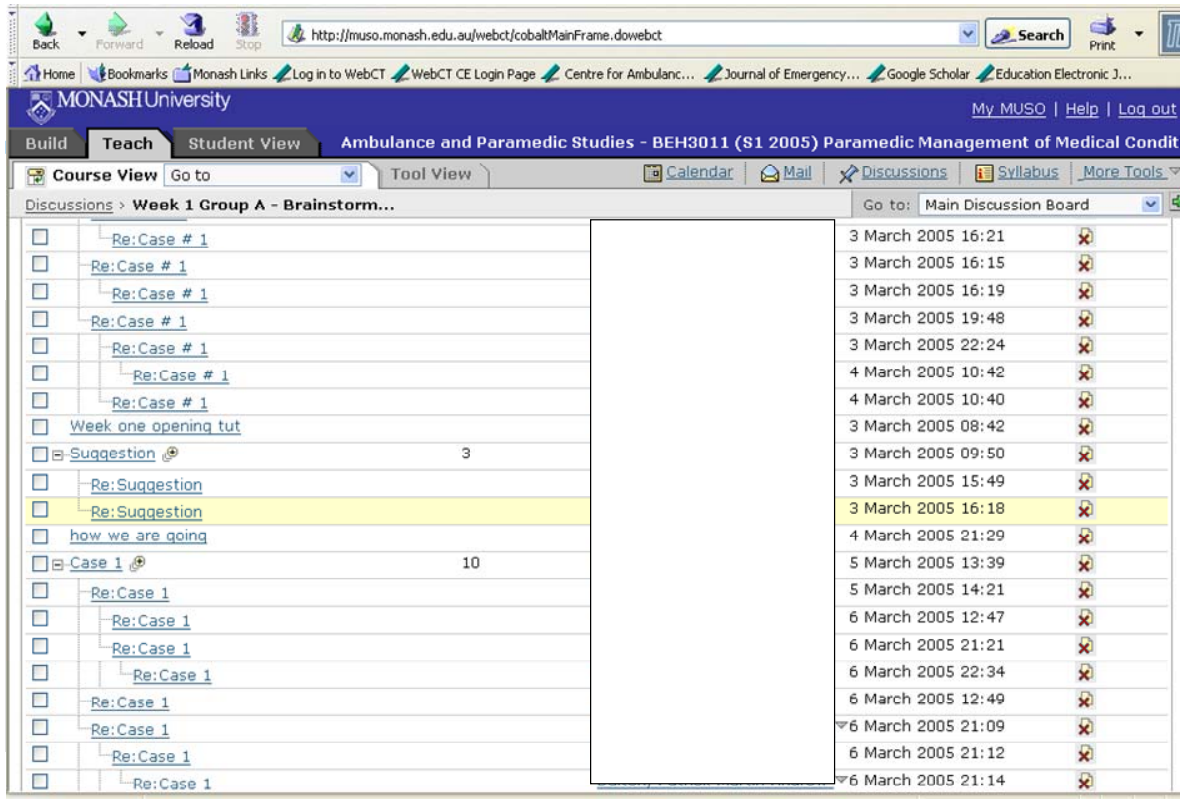

Figure 1: Example of threaded discussions in 'Final Submission' session within WebCT

The use of CBL in e-learning communities does bring about potential adverse consequences. Such as, what measurement and verification takes place to ensure that the learning objectives link with the weekly cases during semester. One solution to counteract this potential pitfall is the development of a content/behavioural table seen in Figure 2 (below). This educational quality assurance table outlines an example from the undergraduate clinical units in the BEH. This type of table provides the author with the flexibility to manipulate the syllabus and curricula requirements into each weekly case.

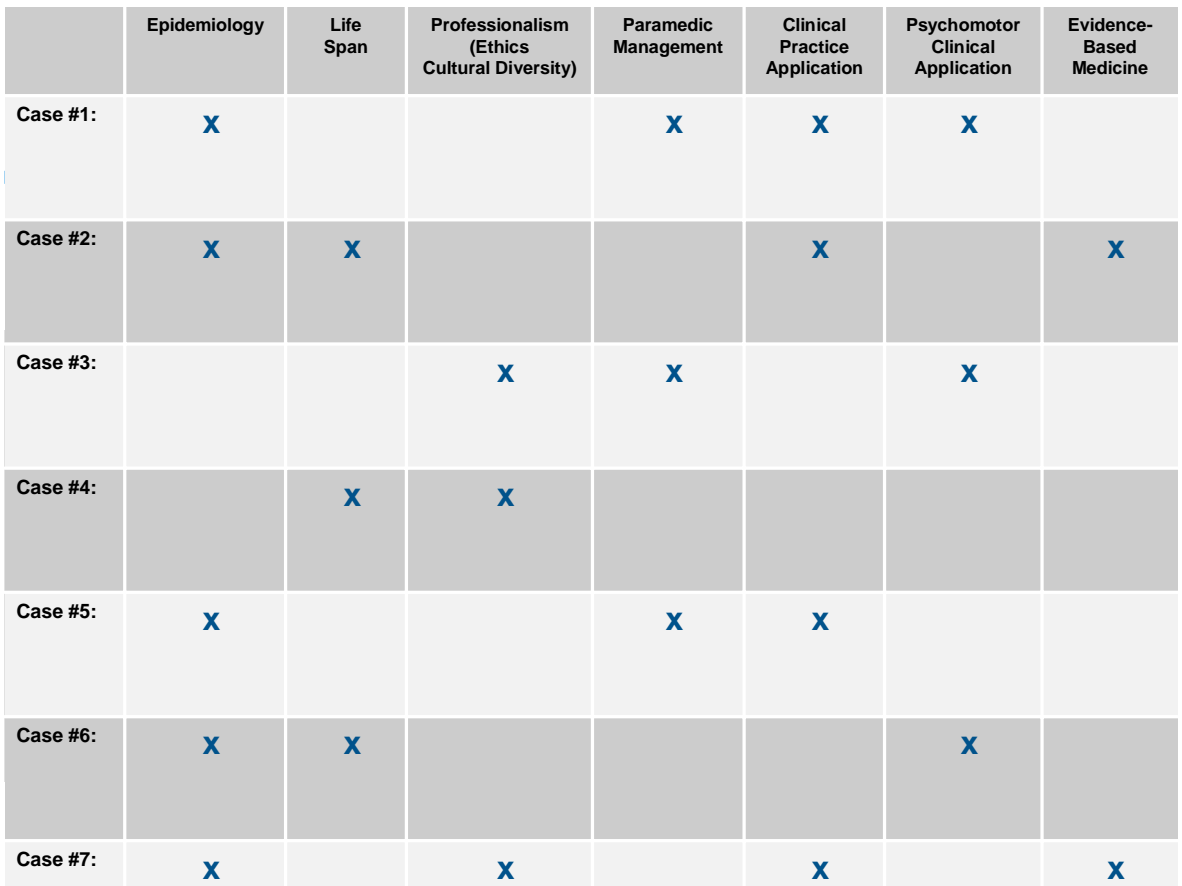

Figure 2: Content/behavioural table 
This content/behavioural table attempts to outline the weekly cases, relevant stages of student/teacher engagement and themes targeted. In many ways this type of quality assurance grid allows teachers a check list ensuring that themes (within a thematic degree) are covered and also identifies areas within themes which have been under-utilised or alternatively over-utilised.

\section{Methods}

This qualitative study was undertaken in single phase by the researcher (lecturing staff member) as a research-led teaching approach comparing $2^{\text {nd }}$ and $3^{\text {rd }}$ year paramedic undergraduate students. Data were collected through open-ended questions from both second and third year BEH groups. Open-ended questions were used to allow students to provide greater alternative responses. The analysis provided a basic foundation of the students' perceptions of CBL in their clinical curricula during semester one, 2005. The research project employed a qualitative design using open-ended questions to assess the student's attitudes and responses to $\mathrm{CBL}$, and was administered to $(n=69) 2^{\text {nd }}$ and $3^{\text {rd }}$ year $\mathrm{BEH}$ students.

A purposive sample of $2^{\text {nd }}$ year $(n=40)$ and $3^{\text {rd }}$ year $(n=29)$ undergraduate BEH students was undertaken. Both student cohorts consisted of a (64\%) female to (36\%) male ratio with a combined median age of 26.5 years. This was commenced at the end of semester one, 2005 academic period (February 2005 and June 2005) prior to all final clinical examinations following ethics approval by Monash University Standing Committee on Ethical Research in Humans.

\section{Results}

The data analysis will now be described with the combined data from both $2^{\text {nd }}$ and $3^{\text {rd }}$ year students. Student responses to open-ended questions underwent thematic analysis as described by Bender \& Ewbank ${ }^{10}$ by three independent experienced qualitative researchers, and the results compared between data sets. These multiple coding approaches or credibility checks are one aspect argued to increase the objectivity and validity of qualitative research. ${ }^{11,12}$ A sample of typical responses from second and third year students is shown below discussing their perceptions of enjoyable learning experience and learning in an online environment:

\section{Enjoyable learning experience}

"CBL gave us the opportunity to see where the theory in lectures fitted in with real world cases" (BEH 3rd year student) ${ }^{16}$

"I think if you can associate a particular clinical situation/presentation with 'real' stories, you are more likely to remember the pertinent points” (BEH 3rd year student $)^{9}$

"It's good to be given a realistic case scenario because it puts you in a position where you look at the case from all angles and bring ideas into play" (BEH 2nd year student) ${ }^{26}$ 
"I was able to make sense of lecture material because it linked to clinical practice on road” (BEH 3rd year student) ${ }^{17}$

"There was no face-to-face interaction with online learning, therefore less motivation to be forced to do or say something” (BEH 3rd year student) ${ }^{21}$

"I dislike Internet CBL because you cannot receive instant feedback about questions” (BEH 3rd year student) ${ }^{23}$

"In person tutes are more effective as they allow for the immediate exchange of information” (BEH 2nd year student) ${ }^{17}$

"There was no face-to-face interaction with online learning, therefore less motivation to be forced to do or say something” (BEH 2nd year student) ${ }^{2}$

\section{Learning in an online environment}

"Can access web info at the same time to research topic" (BEH 3rd year student)3

"Advantage was that since it was online could post responses at any time of day/night” (BEH 3rd year student) ${ }^{18}$

"Doing the work online meant I could fit in the tute work with other work commitments" (BEH 2nd year student) ${ }^{31}$

"Advantage was that since it was online I could post responses at any time of the day/night” (BEH 2nd year student ) ${ }^{29}$

"Convenient, interactive allows for self-directed learning gives people a chance to share information” (BEH 3rd year student) ${ }^{21}$

"I don't have Internet at home, found it slightly difficult to access information” (BEH 3rd year student) ${ }^{14}$

"All on computer - without Internet access at home, often others had answered all questions overnight before I had a chance to look at the case at all” (BEH 2nd year student) ${ }^{26}$

"In person tutes are more effective as they allow for the immediate exchange of information” (BEH 3rd year student) ${ }^{9}$

“Often found it difficult to be online” (BEH 2nd year student) ${ }^{20}$

\section{Discussion}

\section{Enjoyable learning experience}

This study set out to explore the perceptions of undergraduate BEH paramedic students being taught using CBL in a blended model. These questions were adapted to provide a contemporary description of undergraduate student perceptions of CBL and the use of blended teaching methods. The results have suggested that the $2^{\text {nd }}$ and $3^{\text {rd }}$ year BEH students 
generally enjoyed CBL as a teaching and learning paradigm. However, reservations still exist on its 'perfect' delivery via an online learning management system.

The results of this study are supported by the studies by Chadwick et al (13), ${ }^{13}$ Atack \& Rankin ${ }^{13}{ }^{14}$ and Antepohl \& Herzig ${ }^{14,15}$ who found positive findings in their orthodontic, nursing and medical PBL programs. Choi's ${ }^{16}$ study determined that their blended learning environment using PBL was embraced and generally enjoyed by participants. The use of Internet in their program was similar to the use within this CBL project. Their results demonstrated satisfaction with the PBL process, along with the use of the Internet to assist their learning.

A common negative theme identified was the preference for inclusion of more in-classroom learning. It is perhaps difficult to identify whether this caused by direct opposition triggered by their learning styles or a direct dislike for Internet-based learning? Similar findings were also found in the study by Atack \& Rankin $^{14}$ in which the student groups were relieved to have face-to-face lectures in their PBL program.

With high financial demands now being placed on the higher education sector, the need for academic teaching staff to develop flexible learning arrangements has increased dramatically. This has challenged staff and administrators to develop more cost-effective programs, which can be delivered in a more accommodating environment such as via the Internet, whilst increasing the sophistication of educational software. Other areas that have emerged have been programs that involve collegial merging of partnerships, and more efficient ways of conducting teaching and non-teaching activities such as written examinations. ${ }^{17}$

Despite the success of the CBL experience, some elements require further research and analysis, such as how the material is delivered. For example, should the case material and brainstorming sessions be delivered face-to-face or online? Another intriguing facet to this type of educational method is the possible relationship to enjoyment and academic results. Whilst this was not measured in this project others have found promising data, one such example is Moore's ${ }^{18}$ study who found that students who enjoyed a PBL program had similar academic results compared to those in favour of more traditional programs.

\section{Learning in an online environment}

Web-based learning is repeatedly being promoted as a panacea for learners globally. ${ }^{19}$ Evidence now supports the ideal that web-based teaching is enjoyed by many students and is acknowledged in earlier studies. ${ }^{20-25}$ Kennedy $^{26}$ argues the movement of health education becoming 'borderless', and identifies four key areas for online educators: understand their learners, design the learning environment based upon their styles, provide the ongoing support and feedback and continue formative and summative evaluation for all students.

Online teaching and learning principles have many similarities to traditional face-to-face teaching, however there are particular nuances that require teachers to be cognizant of and make the appropriate alterations to their practice. ${ }^{26}$ This research has shown that when online learning strategies are implemented, the role of the learner changes from passive to one who is self-directed and takes responsibility for his or her own learning. Therefore, the teacher's role changes from that of the authoritarian expert to coach or facilitator. The shift occurs from content-driven presentations to shared inquiry between learners and teachers to answer questions and solve problems. The educator guides the discussion with remarks about the learners' responses and may summarise the content at the end of the learning segment rather than dominate the discussion with his or her agenda. ${ }^{27}$ 
Analysis of the qualitative data suggests that for one reason or another, combining face-toface teaching with e-learning was not accepted by all students. The author is aware of the increased individualism created by online education and that with all best intentions and design innovation this cannot guarantee effective and efficient student learning. Online teaching and learning principles have many similarities to traditional face-to-face teaching, however there are particular implications that require teachers to be aware of and make the appropriate alterations to their practice. ${ }^{26}$

Brabazon $^{28}$ argues that too often there is an easy celebration of the online environment which will automatically create a quality SCL environment. Often teachers are unaware that the technology they use is in fact driving their pedagogy, and not the pedagogy directing how they use educational technology. In this particular study it is assumed this pedagogicaltechnological paradox is not occurring, rather a simple acceptance that not all students will support blending teaching environments involving online education.

There is clear disparity with students' views on the use of e-learning, which is interesting since this may not necessarily be related to age or learner generation. This has potential ramifications for teaching and student groups with the advent of impressive new software that allows peer-to-peer file sharing of information but also the advantage of providing 'real time' or 'synchronous' discussions. This would raise further questions on computer access, equity issues, software upgrades and bandwidth requirements.

\section{Limitations of Study}

A number of limitations emerged during the study that demands particular discussion. The study does not identify past clinical teaching and learning experiences, or experiences as clinical health care workers (e.g. nurses or non-emergency paramedic attendants). These specific professional learning background details may have affected the results. The researcher also brought his own personal views, experiences and expectations into the qualitative analysis. Overall, the findings of this study cannot be taken to be representative of lecturing staff teaching CBL programs at large, rather they offer the experiences of this particular group of individuals, but they do provide new levels of understanding of prehospital SCL programs which is important in this specific area of prehospital education.

\section{Conclusion}

Teaching CBL in undergraduate paramedic education is complex and influenced by many different factors, as raised through the findings of this study. The outcomes of this research promote the exploration of the possibilities of developing innovative strategies to overcome these educational barriers. Presently, CBL appears to be a useful and enjoyable teaching and learning tool, however further research should be undertaken to identify what teaching delivery of CBL should be utilised to better meet the students' needs. The findings of this study also suggest that further research should be promoted in other areas of prehospital education and allow similar studies with other universities and health care providers. 


\section{References}

1. Piaget J. Six Psychological Studies. New York: Vintage Books; 1968.

2. Dewey J. Demoracy and Education. An introduction to the philosophy of education. New York: Free Press; 1916.

3. Bruner J. Toward a Theory of Instruction. Cambridge: Harvard University Press; 1966.

4. Vygotsky L. Mind in Society. London: Harvard University Press; 1978.

5. University M. Snapshot of Monash University. 2006 [accessed $18^{\text {th }}$ August]; Available from: http://www.monash.edu.au/about/overview/snapshot.html]

6. Irby D. Three exemplary models of case-based teaching. Academic Medicine. 1994;69(12):947-53.

7. Schmidt HG. Problem-based learning: rationale and description. Medical Education. 1983 Jan;17(1):11-6.

8. Sutyak J, Lebeau R, O'Donnell A. Unstructured Cases in Case-based Learning Benefit Students with Primary Care Career Preferences. The American Journal of Surgery. 1998;175(6):503-7.

9. Thousand J, Villa R, Nevin A. Creativity and collaborative learning: A practical guide to empowering students and teachers. Baltimore: Brookes; 1994.

10. Bender D, Ewbank D. The focus group as a tool for health research: issues in design and analysis. Health Transition Review. 1994;4(1):63-79.

11. Barbour R. Checklists for improving rigour in qualitative research: a case of the tail wagging the dog? British Medical Journal. 2001;322(7294):1115-7.

12. Elliot R, Fischer C, Rennie D. Evolving guidelines for publication of qualitative research studies in psychology and related studies. British Journal of Clinical Psychology. 1999;38(3):215-29.

13. Chadwick SM, Bearn DR, Jack AC, O'Brien KD. Orthodontic undergraduate education: developments in a modern curriculum. European Journal of Dental Education. 2002 May;6(2):57-63.

14. Atack L, Rankin J. A descriptive study of registered nurses' experiences with webbased learning. Journal of Advanced Nursing. 2002 Nov;40(4):457-65.

15. Antepohl W, Herzig S. Problem-based learning versus lecture-based learning in a course of basic pharmacology: a controlled, randomized study. Medical Education. 1999 Feb;33(2):106-13.

16. Choi $\mathrm{H}$. A problem-based learning trial on the Internet involving undergraduate nursing students. Journal of Nursing Education. 2003 Aug;42(8):359-63.

17. Stromso HI, Grottum P, Hofgaard Lycke K. Changes in student approaches to learning with the introduction of computer-supported problem-based learning. Medical Education. 2004 Apr;38(4):390-8.

18. 18. Moore GT. The effect of compulsory participation of medical students in problem-based learning. Medical Education. 1991 Mar;25(2):140-3.

19. Cragg CE, Edwards N, Yue Z, Xin SL, Hui ZD. Integrating Web-based technology into distance education for nurses in China: computer and Internet access and attitudes. CIN: Computers, Informatics, Nursing. 2003 SepOct;21(5):265-74.

20. Andrusyszyn MA, Iwasiw C, Goldenberg D. Computer conferencing in graduate nursing education: perceptions of students and faculty. Journal of Continuing Education in Nursing. 1999 Nov-Dec;30(6):272-8.

21. Billings DM, Rowles CJ. Development of continuing nursing education offerings for the World Wide Web. Journal of Continuing Education in Nursing. 2001;32(3):107-13. 
22. Curran V. An evaluation report: computer-mediated continuing medical education at a distance. Newfoundland: Memorial University; 1998.

23. Daugherty M, Funke B. University faculty and student perceptions of web-based instruction. Journal of Distance Education. 1998;13(1):21-39.

24. Kenny A. Untangling the web; barriers and benefits for nurse education; an Australian perspective. Nurse Education Today. 2000;20(5):381-8.

25. Washer P. Barriers to the use of web-based learning in nurse education. Nurse Education Today. 2001/8;21(6):455-60.

26. Kennedy DM. Standards for online teaching: lessons from the education, health and IT sectors. Nurse Education Today. 2005 Jan;25(1):23-30.

27. Phillips JM. Strategies for active learning in online continuing education. Journal of Continuing Education in Nursing. 2005 Mar-Apr;36(2):77-83.

28. Brabazon T. Digital Hemlock: Internet education and the poisoning of teaching. Sydney: UNSW Press; 2002.

This Article was peer reviewed for the Journal of Emergency Primary Health Care Vol.4, Issue 3, 2006

\section{Author Disclosure}

The author has no financial, personal or honorary affiliations with any commercial organization directly involved or discussed in this study. 